\title{
Y Rizoma \\ As manchetes jornalísticas na página do Podemos: agendamento e singularidade
}

Resumo: O objetivo deste texto é refletir sobre uma das táticas de comunicação política do partido espanhol Podemos: a veiculação de manchetes noticiosas, de instituições jornalísticas variadas, acompanhadas por comentários políticos próprios. Busca-se como referência conceitual as teorias do agendamento e do jornalismo como forma de conhecimento. A metodologia consiste na comparação entre título de manchete e comentário do partido, à luz da teoria do jornalismo de Genro Filho (2012), com ênfase nas disputas de sentido em torno de determinado fato social noticiado. Apesar do foco no caso do Podemos, a intenção do texto é contribuir nos debates sobre comunicação política em sua relação com o jornalismo.

Palavras-chave: Agendamento; Comunicação Política; Podemos; Notícia.

\section{Los titulares de periódicos en la página de Podemos: Agenda Setting y singularidade}

Resumen: El propósito de este trabajo es reflexionar sobre una de las tácticas de comunicación política del partido español Podemos: la difusión de titulares de noticias, de diversas instituciones periodísticas, acompañadas de comentários políticos propios. Se tiene como referencia conceptual las teorías de Agenda Setting y del periodismo como forma de conocimiento. La metodología consiste en comparar los titulares y los comentarios, basada em la teoria del periodismo de Genro Filho (2012), con énfasis en las disputas de sentido sobre cierto hecho social. A pesar del enfoque en el caso de Podemos, la intención del texto es contribuir a los debates sobre la comunicación política en su relación con el periodismo.

Palabras clabe: Agenda Setting; Comunicación Política; Podemos; Notícia.

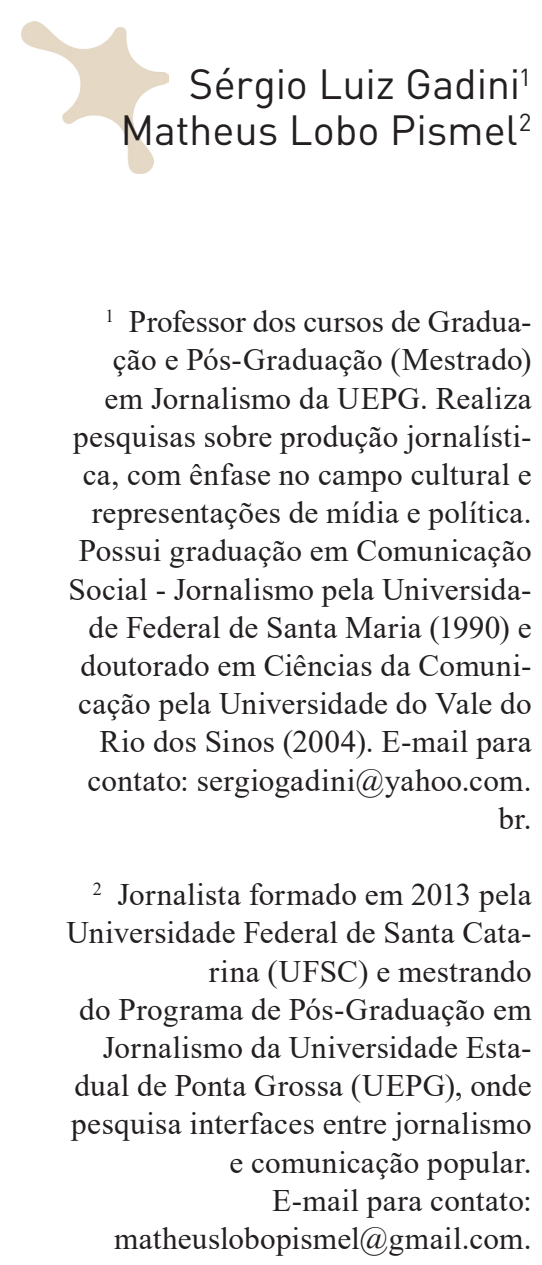

\section{News headlines on Podemos page: Agenda Setting and singularity}

\begin{abstract}
The purpose of this text is to reflect on one of the tactics of political communication of the Spanish party Podemos: the publication of news headlines, of varied journalistic institutions, accompanied by political commentaries of their own. The conceptual references are Agenda Setting and
\end{abstract}



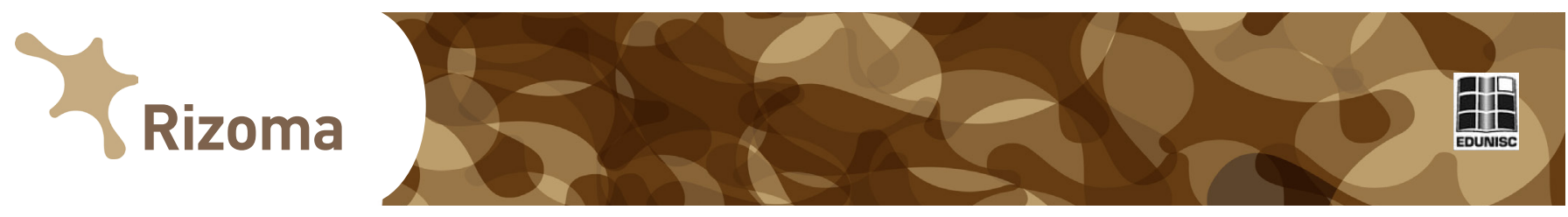

theory of journalism as social knowledge. The methodology consists of the comparison between headline and party commentary, in light of Genro Filho's theory of journalism (2012), with emphasis on the disputes of meaning around a certain social fact reported. Despite the focus in the case of Podemos, the intention of the text is to contribute in the debates on political communication in its relation with the journalism.

Keywords: Agenda Setting; Political Communication; Podemos; News.

\section{Introdução}

Este texto busca se aproximar conceitualmente de uma das táticas de comunicação política do partido espanhol Podemos: a postagem comentada de manchetes noticiosas, copiadas cotidianamente de diferentes jornais online, em seu canal de Facebook. A abordagem busca olhar para o processo de agendamento temático (MCCOMBS, 2009), para a relação entre os campos jornalístico e político e para a notícia como forma de conhecimento cristalizada no singular (GENRO FILHO, 2012).

Em pouco mais de dois anos de existência, o Podemos se tornou o partido de esquerda com maior projeção política na Europa. Nas eleições presidenciais de 26 de julho, a coalizão que organizava aparecia em segundo lugar até as últimas pesquisas, o que a colocava com chances reais de formar um novo governo espanhol. O resultado final surpreendeu a todos e não confirmou as expectativas, mas consolidou o partido como terceira força política da Espanha, atrás apenas dos tradicionais Partido Popular (PP) e Partido Socialista Operário Espanhol (PSOE), que polarizam as eleições do país há três décadas.

A curta história do Podemos remonta às manifestações antiausteridade e antiestablishment que tomaram as praças da Espanha em 2011 e ficaram conhecidos como 15-M ou Indignados. Tendo participado das mobilizações, as principais lideranças do partido, entre elas o cientista político Pablo Iglesias, apostaram na necessidade de "converter a indignação em mudança política" (PÚBLICO, 2014) a partir de uma plataforma a ser lançada às eleições europeias e nacionais.

A relação dos dirigentes do Podemos com os meios e as tecnologias de comunicação é fundamental para a compreensão do fenômeno político. Antes de se tornar a principal figura pública do partido, Pablo Iglesias construía sua imagem nos meios de comunicação tradicionais e alternativos desde 2003, tanto como comentarista político quanto como apresentador de programas de debates. Em 2013, o cientista político já era figura pública consolidada em canais tradicionais e paralelamente apresentava dois programas independentes, La Tuerka, online, e Fort Apache, no canal público iraniano HispanTV. Foi o que pesou para que fosse escolhido pelo Podemos como cabeça da lista de candidatos ao Parlamento Europeu (sendo eleito eurodeputado) e, posteriormente, como secretário-geral do partido em um processo informatizado de primárias. Com o rápido crescimento do Podemos, suas aparições na imprensa aumentaram na mesma proporção, não só 

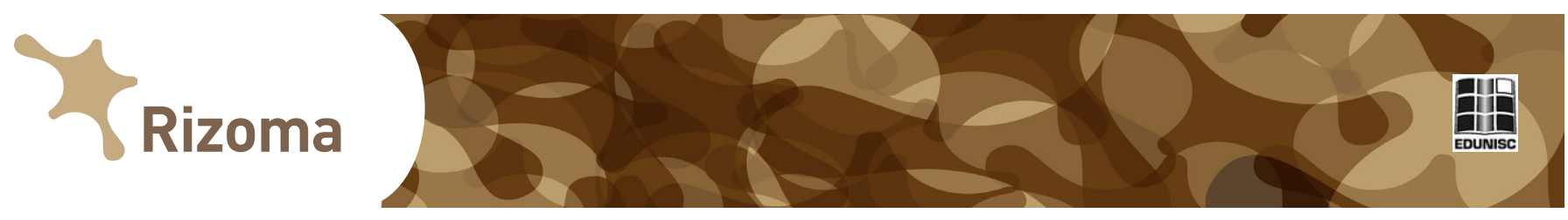

como apresentador ou comentarista, mas como fonte importante (e muitas vezes indesejada) do campo político.

Além da estratégia de acumular capital social e político através da mídia, o Podemos é reconhecido por sua capacidade de incorporar novas tecnologias à política cotidiana; tanto na organização interna, para maior participação online dos ativistas e simpatizantes, quanto nas diferentes redes sociais. Para se ter uma ideia, sua página do Facebook dispõe hoje (agosto de 2016) de quase 1,1 milhão de curtidas, contra 162 mil do PP e 134 mil do PSOE.

Dentro do universo de postagens diárias na página do Facebook, podem ser traçados dois tipos principais: i) institucional, conteúdos mais estreitos ao partido, como propostas ou comunicados em vídeo, imagem e/ou texto, e sem referência direta ao campo midiático; e ii) clipagem-comentário, conteúdos transferidos de veículos jornalísticos. Nesta segunda categoria, o Podemos utiliza manchetes noticiosas, de diferentes veículos de comunicação, para comentar os acontecimentos da agenda política ou pública. As postagens "clipagem-comentário" envolvem desde notícias diretamente relacionadas ao partido e suas ações até assuntos gerais do país.

Uma observação inicial mostra que a quantidade de notícias comentadas na página do Podemos é substancialmente maior do que as de outros partidos espanhóis, nas quais tende a prevalecer conteúdos institucionais ou clipagem de aparições. Além disso, a equipe de comunicação do partido poderia simplesmente postar os links das notícias, mas a técnica é mais elaborada: montam uma manchete (a partir de captura de tela), com foto, título, linha fina, legenda (se houver) e logo do jornal online clipado, sem qualquer trecho ou link ao texto de origem.

Imagem 1: Exemplo da postagem "clipagem-comentário" na página do Podemos em 14/08/2016

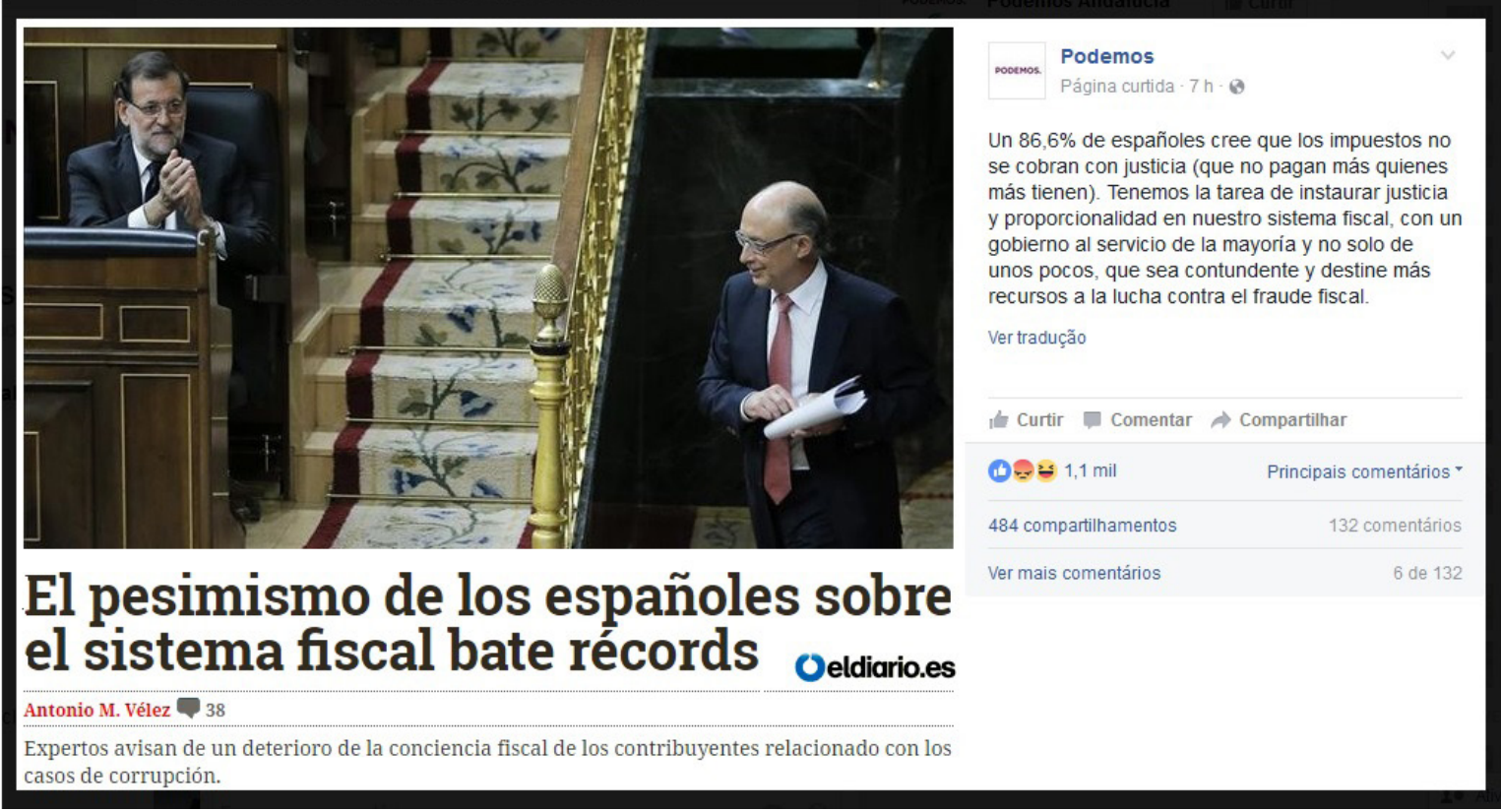

Fonte: Fanpage de Podemos 

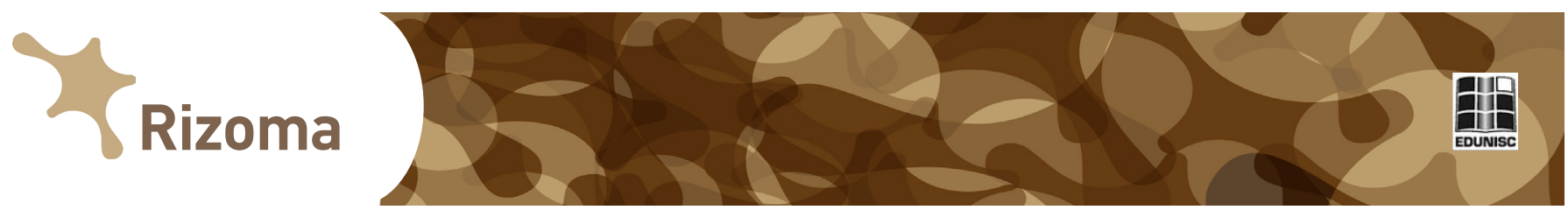

Imagem 2: Exemplo da postagem "institucional" na página do Podemos em 22/07/2016

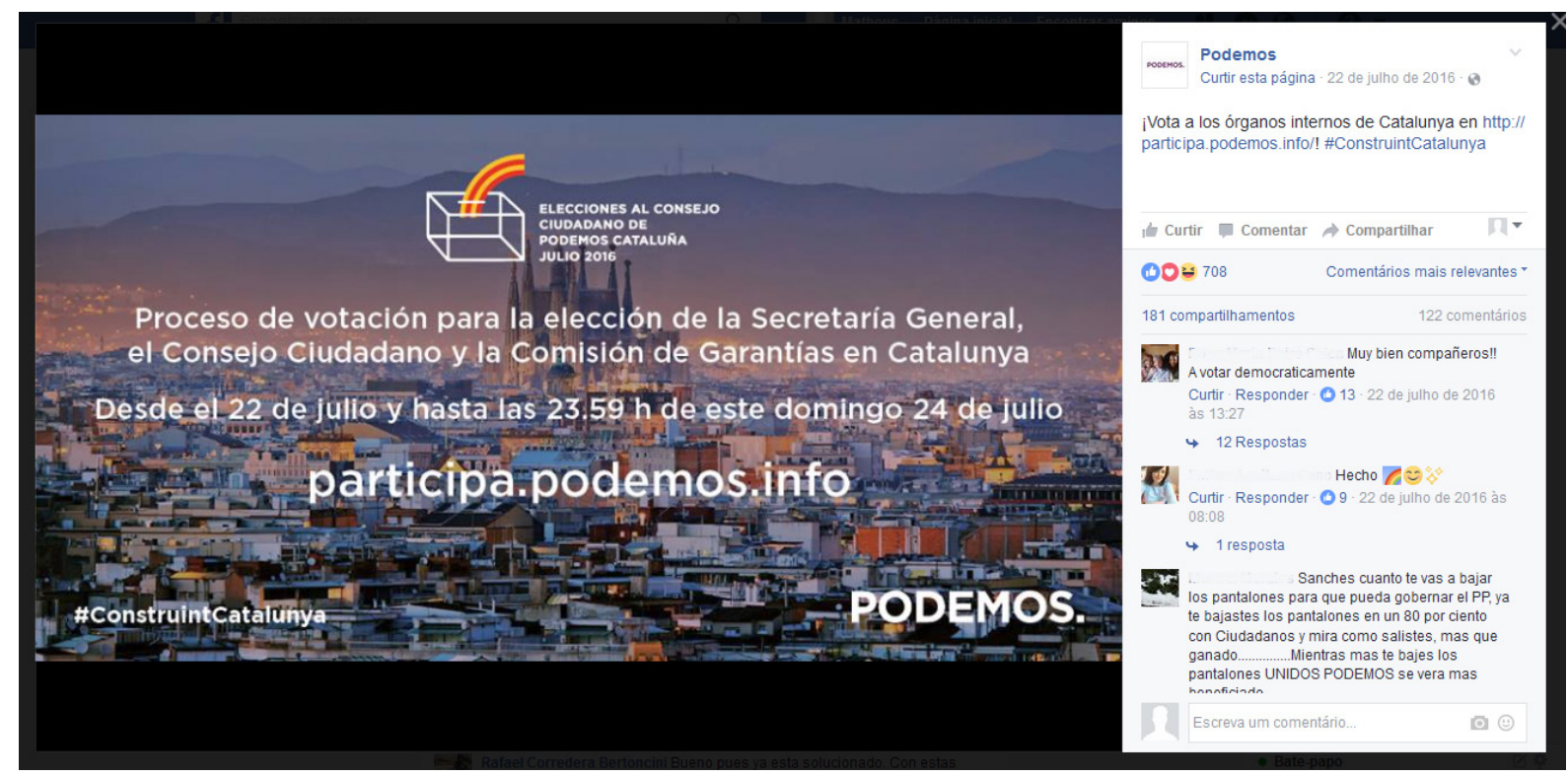

Fonte: Fanpage de Podemos

Devido ao caráter exploratório deste texto, não há levantamentos quantitativos que ilustrem o peso de cada tipo de postagem na página do Podemos, tanto entre elas quanto em relação a outros partidos. O objetivo é iniciar a discussão e, a partir das considerações acima, tentar apontar abordagens teóricas para possíveis análises da notícia enquanto elemento estratégico da comunicação política nas redes sociais atualmente, a partir do caso notável do Podemos espanhol. O problema de fundo se encontra na intersecção entre jornalismo e política, entre aberturas e fechamentos de sentido.

Foram selecionadas para análise três postagens "clipagem-comentário", dos meses de maio, junho e agosto de 2016, sendo duas notícias do jornal tradicional El País e uma do portal Público, o qual registra maior proximidade política com o Podemos. Buscou-se notícias de características de conteúdo distintas: divulgação de dado estatístico sobre realidade espanhola, negociações do presidente Mariano Rajoy (PP) com União Europeia e reconhecimento positivo das prefeituras compostas pelo Podemos. A metodologia de análise consiste em comparar o título da manchete do diário com o comentário do partido, a luz da teoria do jornalismo de Genro Filho (2012), estruturada sobre a tríade singularidade, particularidade e universalidade. A ênfase está nas disputas de sentido em torno de determinado fato social noticiado.

\section{Agenda da mídia, da política e do público}

A teoria do agendamento foi desenvolvida inicialmente por Maxwell McCombs e Daniel Shaw a partir de um estudo sobre a influência dos meios de comunicação nas eleições presidenciais estadunidenses de 1968. Inicial- 

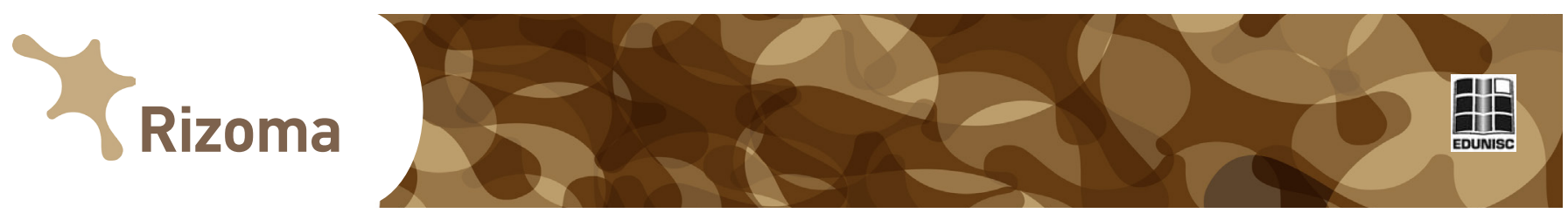

mente uma hipótese, centenas de estudos empíricos posteriores a tornaram uma das principais teorias sobre os efeitos da mídia. McCombs (2009) mostra que, ao destacar alguns assuntos e ofuscar outros, os mass media podem moldar a agenda pública.

Os efeitos de agendamento são o resultado combinado entre o destaque (saliência) dos temas, conferido pela mídia, e a relevância psicológica desses temas para o público. Nessa relação operam uma série de condições contingentes, sendo a principal delas o grau da "necessidade de orientação" do público em relação ao assunto específico. "Quanto maior a necessidade de orientação que as pessoas têm no âmbito dos assuntos públicos, maior é a probabilidade delas atentarem para a agenda da mídia" (MCCOMBS, 2009, p. 94). Para McCombs (2009), os mass media são responsáveis por um processo de aprendizagem "contínuo e virtualmente invisível":

\begin{abstract}
Ao longo de relativamente poucas semanas, a saliência de tópicos veiculados na mídia noticiosa é absorvida por parte significativa do público. (...) Elas [as pessoas] aprendem um montão de fatos, muitos dos quais elas incorporam em suas imagens e atitudes sobre uma variedade de objetos. Elas também aprendem sobre os mais importantes temas do momento, incorporando a agenda dos mass media em suas próprias agendas dos tópicos centrais do que a sociedade enfrenta. (MCCOMBS, 2009, p. 80).
\end{abstract}

Analiticamente, McCombs (2015) divide em dois ${ }^{3}$ principais niveis de agendamento: o primeiro trata do quê é transferido de uma agenda para outra; o segundo é sobre como os temas aparecem, seus atributos. Neste sentido, "ao se mapear o impacto da mídia nas opiniões, é crucial distinguir a contribuição da atenção geral da mídia para um tema, o agendamento de primeira dimensão, da maneira como um tema é enquadrado na mídia, o agendamento de segunda dimensão" (MCCOMBS, 2009, p. 190). Isso significa, para McCombs (2009, p. 191), que "a mídia não só nos diz sobre o que pensar, mas também nos diz como pensar sobre os assuntos".

Sendo parte do público que recepciona os fatos sociais produzidos pela mídia, os partidos políticos também são influenciados pela agenda noticiosa. Além disso, conforme McCombs (2009, p. 182), a teoria do agendamento é sobre a transferência de saliência de uma agenda para outra, não necessariamente apenas entre mídia e público. Há várias agendas organizadas socialmente. Nosso interesse está na relação entre a agenda da mídia e a do campo político, incluindo o Podemos, e deste com o público. É possível lançar algumas perguntas a partir da teoria para nosso objeto: qual o grau de adesão da agenda podemista à agenda midiática? Há coincidência de saliência dos temas escolhidos pelo partido? Quais os contingentes na forma e no conteúdo das notícias que permitem ou restringem o agendamento? Quais outras situações contingentes do próprio partido que influenciam? O Podemos tenta intervir nas características (enquadramento) dadas pela mídia aos temas?

Há também um caminho inverso passível de análise. Ao mesmo tempo em que é agendado pela mídia, o partido tem suas próprias estratégias para destacar e caracterizar determinados temas para pautar a própria mídia. Como aponta McCombs (2009, p. 153), "refletir sobre as origens da agenda 

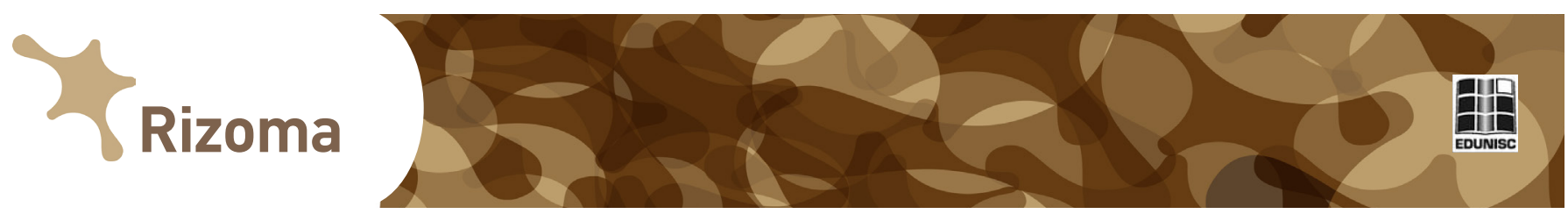

mídia faz lembrar muitas outras agendas, tais como as agendas de temas e de questões políticas". Estas agendas seriam um dos três elementos-chave na definição da agenda midiática, ou seja, "as principais fontes que fornecem a informação para as matérias", junto das "normas e as tradições do jornalismo" e de outros veículos noticiosos (MCCOMBS, 2009, p.181).

Considerando que as páginas de Facebook das organizações são ferramentas de comunicação política, a questão principal é saber o potencial desse tipo de postagem na estratégia de diálogo do Podemos com suas bases e as redes sociais, em geral. A hipótese é de que o Podemos busca intervir na agenda pública e política a partir da ressignificação dos temas agendados pela mídia. Situada a estratégia nesta posição, a definição da notícia como forma de conhecimento cristalizada no singular, proposta por Genro Filho (2012), ajuda a complexificar o objeto.

\section{O singular nas manchetes compartilhadas}

Para Genro Filho (2012, p. 32), o "jornalismo informativo" surge do casamento entre o "novo tecido universal das relações sociais produzido pelo advento do capitalismo" e os "meios industriais de difundir informações". O jornalismo inaugura um novo tipo de apropriação simbólica da realidade, uma nova forma de conhecimento social. Esse conhecimento é caracterizado pela "apropriação do real pela via da singularidade, ou seja, pela reconstituição da integridade de sua dimensão fenomênica" (GENRO FILHO, 2012, p. 58). O singular é o fenômeno único, irrepetitível, a forma do novo. O jornalismo, assim, se diferencia da ciência e da arte, que têm como momentos dominantes as categorias da universalidade e particularidade, respectivamente.

O jornalismo não produz um tipo de conhecimento, tal como a ciência, que dissolve a feição singular do mundo em categorias lógicas universais, mas precisamente reconstitui a singularidade, simbolicamente, tendo consciência que ela mesma se dissolve no tempo. O singular é, por natureza, efêmero. O jornalismo tampouco elabora uma espécie de representação cujo aspecto singular é arbitrário, projetado soberanamente pela subjetividade do autor, tal como acontece na arte, onde o típico é o eixo fundamental de contato com a realidade. (GENRO FILHO, 2012, p. 65).

O autor explica ainda que "o processo de significação produzido pelo jornalismo" é determinado por duas variáveis: "l) as relações objetivas do evento, o grau de amplitude e radicalidade do acontecimento em relação a uma totalidade social considerada; 2) as relações e significações que são constituídas no ato de sua produção e comunicação" (GENRO FILHO, 2012, p. 65). Trata-se, conforme o teórico, da dialética entre o objetivo e o subjetivo que está na essência da informação jornalística. Ainda que a notícia seja mediada por um sujeito, ela tende a se cristalizar na face objetiva do evento, a singularidade.

O jornalismo não tenta dissolver esse fenômeno singular dentro de um esquema de sentido geral, pelo contrário, busca reconstituí-lo por meio de técnicas da linguagem. Isso faz com que a notícia se aproxime da percepção cotidiana, realizando uma espécie de simulação da imediaticidade. Em síntese, conforme 


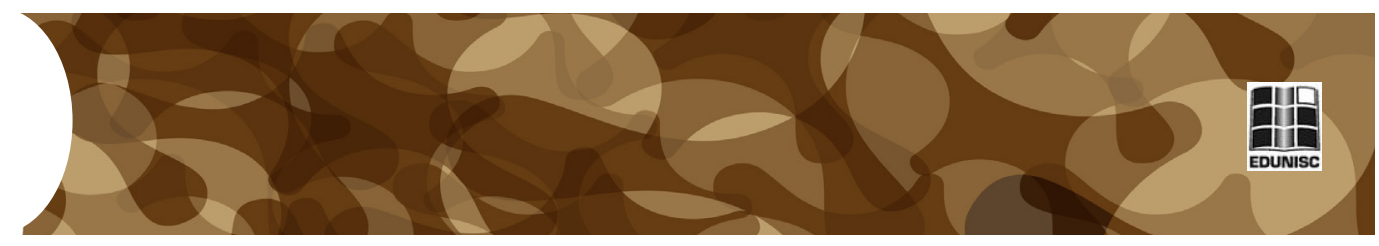

Pontes (2015, p. 362, grifo nosso), "os fatos sociais apresentam a dimensão singular e essa é apreendida e ressignificada pelo jornalismo. É essa dimensão objetiva que permanece na relação com o público (a abertura de sentido)".

Trazendo a discussão para nosso problema, pode-se afirmar que é essa abertura de sentido, propiciada pela reconstituição do fenômeno singular, que torna a notícia um elemento estratégico para a comunicação do Podemos e de qualquer outra organização política. Se o sentido está aberto, em menor ou maior grau, é possível disputar sua significação social. A linguagem jornalística não permite que o veículo dote de plena significação uma notícia. Tratando-se apenas de uma manchete (título, foto, legenda), a fixação de sentido, assim como seu grau de conhecimento, tende a ser ainda menor. É nesta abertura de sentido que o Podemos busca propor mediações particulares e sentidos gerais para os eventos do cotidiano, tarefa imprescindível na luta por hegemonia social. Vejamos no exemplo abaixo:

Imagem 3: Exemplo de mediação e fixação de sentido na página do

\section{Podemos}

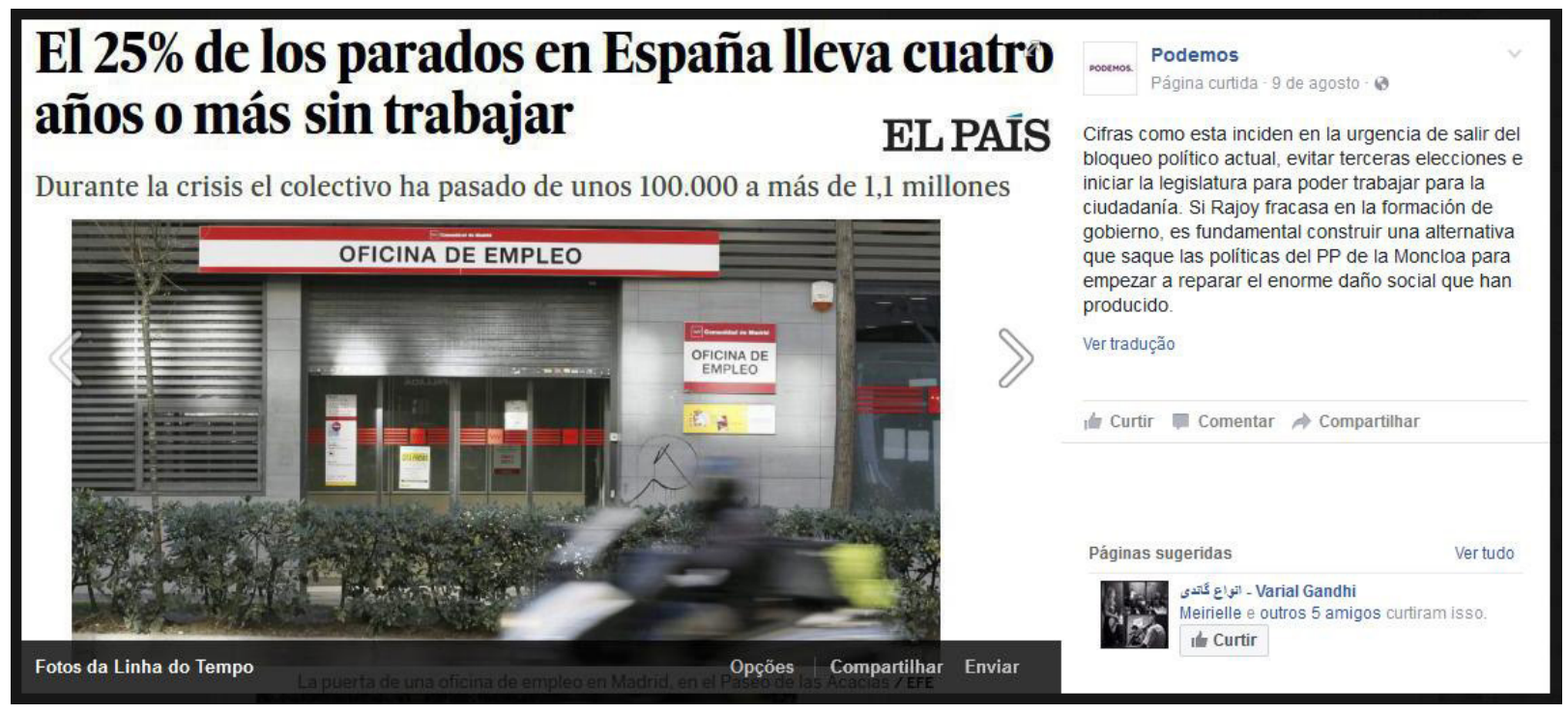

Fonte: Fanpage de Podemos

O título diz que " $25 \%$ dos desempregados na Espanha estão há quatro anos ou mais sem trabalhar" e a linha de apoio que "durante a crise o grupo passou de cerca de 100.000 a mais de 1,1 milhões". E o comentário do Podemos, ao lado: "Cifras como esta expõem a urgência de sair do bloqueio político atual, evitar terceiras eleições e iniciar o mandato para poder trabalhar para a cidadania. Se Rajoy [atual presidente e vencedor das últimas eleições] fracassa na formação de um governo, é fundamental construir uma alternativa que tire as políticas do PP de la Moncloa [palácio do governo] para começar a reparar o enorme dano social que produziram". Quer dizer, a manchete, ainda que carregue uma informação muito forte, não tem em si sentido dado em relação, por exemplo, às causas do desemprego e às possibilidades de combatê-lo. Não há mediações que permitam nem um conhecimento mais aprofundado da 


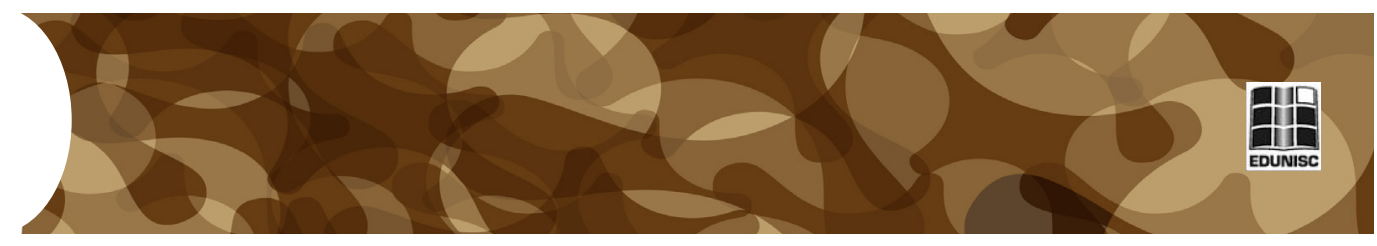

realidade e nem o esboço de uma posição ético-política frente ao problema. O comentário do partido, de forma sintética, mira em uma das contextualizações possíveis, a questão do impasse que vive a política espanhola: o PP foi o partido mais votado, mas não obteve maioria para formar governo e tem de negociar com outras forças. Como os diálogos estão travados, há o risco de ser realizada mais uma eleição nacional, o que agravaria o período de indefinição institucional. Sobre este contexto, introduzido pela singularidade do fato social, o Podemos faz sua intervenção política: novas eleições são prejudiciais para a Espanha; os partidos devem acelerar as conversas para a formação de um governo; se o PP fracassa, é necessário que as diferentes forças da oposição se ponham de acordo para um governo alternativo.

Em outro exemplo, o título da notícia de 06/05/2016 diz: "Rajoy oferece um ajuste a mais a Bruxelas para evitar a multa por déficit". A linha de apoio complementa que: "A UE [União Europeia] considera atrasar a sanção até depois das eleições para não interferir na campanha". O comentário do Podemos afirma que "a austeridade de Rajoy não só prejudica a economia de todos os lares espanhóis, que têm de suportar os cortes: além disso, mostra que não serve para resolver a dívida pública. Não se trata de maquiar contas para as eleições, mas sim de obter melhorias estáveis para o país". A manchete, novamente, se abre para diferentes possibilidades de interpretação. Para um neoliberal, poderia significar um esforço do governo espanhol em cumprir suas obrigações com a União Europeia, mas o Podemos aproveita da abertura de sentido do fato singular, preservada pelo jornal, para afirmar sua posição antiausteridade.

Imagem 4: Exemplo da postagem antiausteridade na página do Podemos

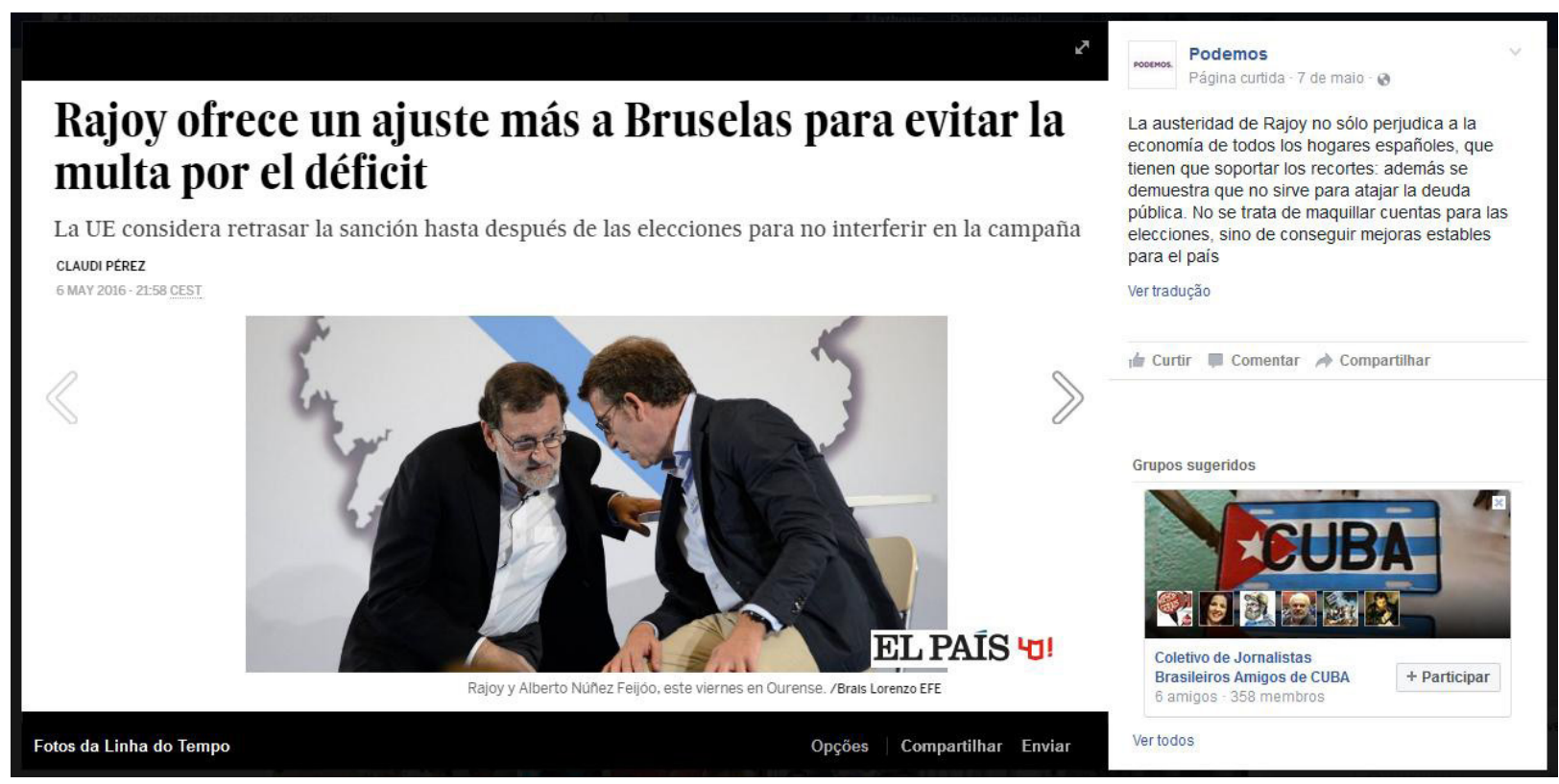

Fonte: Fanpage do Podemos

Em postagem do dia 13 de junho de 2016, sob título de "ONU louva Colau e Carmena", o interesse do Podemos está em visibilizar as "prefeituras da mudança", comandadas por Ada Colau, em Barcelona, e Manuela 


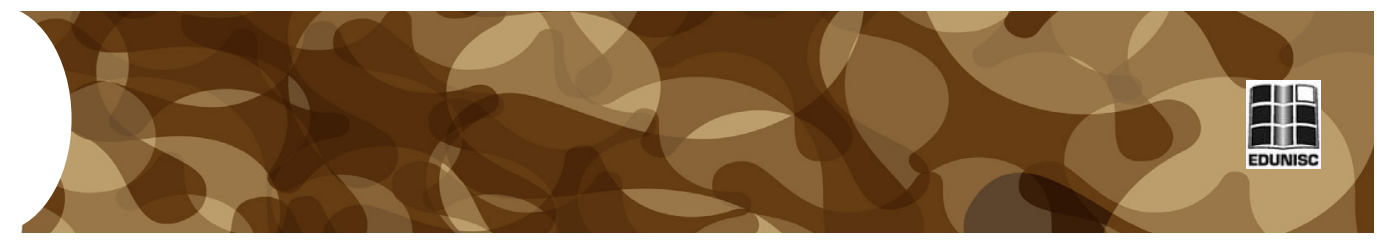

Carmena, em Madrid, ambas em composição com o partido. A notícia, publicada originalmente pelo portal Público, trata do elogio, por parte do Alto Comissariado das Nações Unidas para os Direitos Humanos, às prefeituras que promovem políticas de acolhida e apoio aos refugiados que chegam à Europa. O comentário do Podemos aproveita o gancho, e o prestígio internacional da ONU, para criticar as políticas do presidente Mariano Rajoy e seu partido no âmbito da União Europeia. "Enquanto o PP apoiava um acordo imoral com a Turquia, em Madrid e Barcelona se aprovavam medidas para oferecer centros de realocação para refugiados". Este acordo, que seria revisto posteriormente, pretendia expulsar refugiados que buscassem abrigos na Europa. Neste caso, o sentido da manchete em si é mais fechado: ONU aprova políticas para refugiados de prefeituras apoiadas pelo Podemos. O comentário, no entanto, tenta mediar este acontecimento específico com as políticas defendidas pelo PP a nível nacional e continental, as quais vão em sentido oposto ao defendido pela ONU. Esta conexão entre o singular e o particular não está dada de imediato na manchete, pelo contrário, é proposta pela intervenção do partido na postagem. Segue abaixo o referido registro:

Imagem 5: Exemplo de conexão entre o singular e o particular na página do Podemos

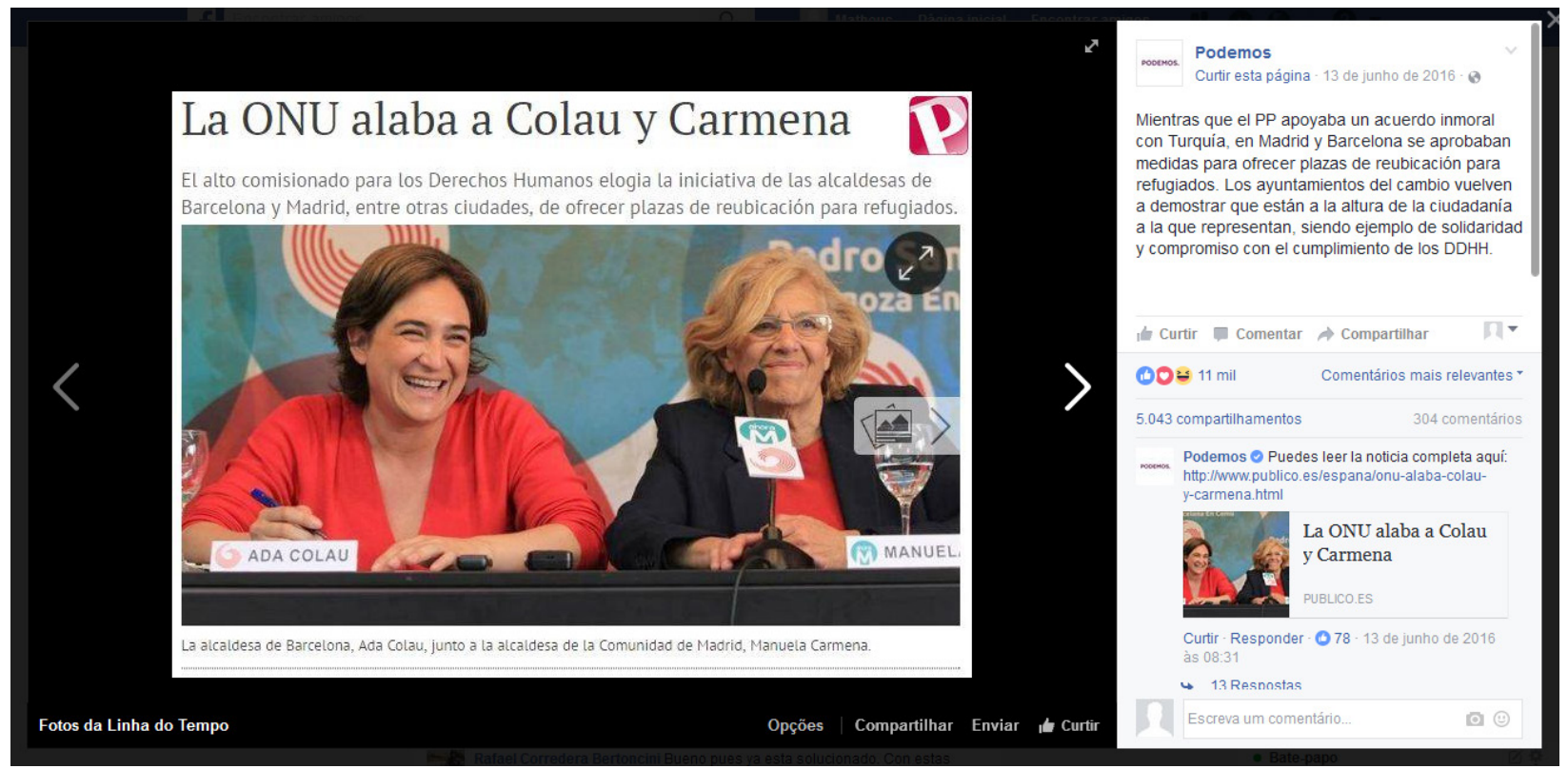

Fonte: Fanpage do Podemos

Com os exemplos, tentamos mostrar que, se a produção jornalística, em seus diferentes gêneros e especialmente na notícia, "guarda o potencial de ressignificar os fatos sociais e de apresentar a complexidade das mediações envolvidas em cada um deles" (PONTES, 2016, p. 161), os atores políticos da sociedade civil podem buscar ressignificar as notícias e, na maioria das vezes, sintetizar as mediações envolvidas na direção de determinado interesse contextual.

Por ser uma forma de conhecimento e, portanto, uma relação subjetiva com o mundo, o jornalismo também difunde ideias, que podem ser incorporadas 


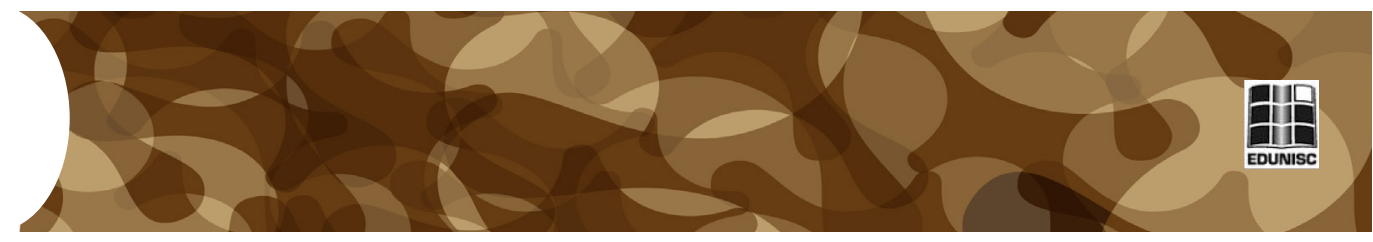

e justificar determinadas práticas do sujeito e da sociedade, ou seja, ideologias (PONTES, 2016). São ideias que podem se vincular, de maneira contraditória e não mecânica, a diferentes posições ético-políticas. Neste sentido, os exemplos deixam claro que o Podemos enfatiza uma intervenção política em detrimento de um conhecimento mais aprofundado sobre o fato social. Até que ponto uma manchete isolada pode ser considerada forma de conhecimento? O interesse do Podemos é puramente ideológico? Ao abrir mão de buscar mediações objetivas e subjetivas que determinam a essência do acontecimento, o Podemos parece enfatizar a dimensão ideológica propiciada pela abertura de sentido para justamente buscar um fechamento com sua própria significação. Isso não significa que haja uma oposição rígida entre conhecimento e ideologia, e nem que o partido "manipule" os fatos. Este "problema" apenas ilustra as diferenças entre a notícia jornalística e a comunicação política de qualquer organização. Enquanto os jornais, em tese, reconstituem os acontecimentos sociais e possibilitam aos sujeitos certa margem de liberdade interpretativa, os partidos políticos lutam justamente para que essa interpretação seja aderente a suas propostas e princípios.

Por fim, ressalta-se que o Podemos clipa manchetes principalmente de grandes diários comerciais, de orientações editorais variadas, ainda que também se notem veículos novos e independentes. Esse aspecto do problema aponta para a discussão sobre posições de legitimidade dentro do campo jornalístico. Para além da discussão sobre abertura de sentido a partir do singular, tratada acima, seria preciso considerar as posições de poder de cada veículo dentro do campo, que garantem maior ou menor credibilidade à notícia utilizada na postagem. Em outras palavras, por mais que o projeto político-editorial do El País seja antagônico às aspirações do Podemos, o partido tenta se utilizar do capital simbólico do jornal (maior do país) para reforçar sua própria intervenção a partir da notícia escolhida. No caso de portais jornalísticos menores, de linhas editorais progressistas, como El Diario e Público, que ainda hospeda colunas e programas audiovisuais de dirigentes do Podemos, a relação também se assenta no capital simbólico jornalístico, mas a partir de outras posições no campo. Além disso, devido à maior proximidade ideológica, estes jornais podem eventualmente tratar de assuntos ou editar manchetes mais interessantes ao partido. Essa poderia ser uma terceira abordagem a ser aprofundada em estudos subsequentes, possibilitando um olhar mais estrutural e sociológico para a estratégia política analisada.

\section{Considerações finais}

O comentário público de assuntos cotidianos é uma das tarefas mais antigas dos partidos políticos. Em geral, esses temas vêm à tona e podem ou não ser agendados pela mídia, por isso as notícias tornaram-se também matéria-prima de análises e intervenções políticas. Neste sentido, não há grande novidade no conteúdo da estratégia do Podemos. Por outro lado, apontamos que a forma com que o partido leva a cabo essa tarefa deixa visível o reconhecimento da centralidade da produção de notícias pelos meios de comunicação na contemporanei- 


\section{Tizoma}

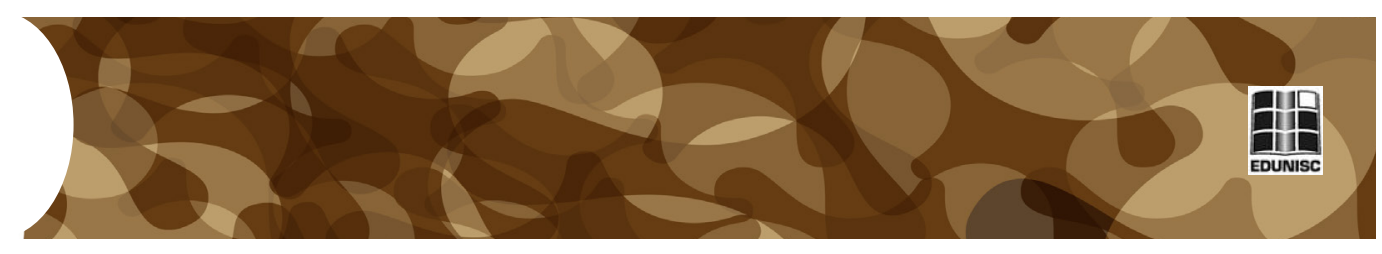

dade. O Podemos não apenas comenta fatos sociais ou notícias quando o assunto lhes toca diretamente, mas as utiliza como gancho para intervir na política cotidianamente. Além disso, o formato da postagem, com capturas de tela de sites noticiosos estabelecidos, admite e busca se aproveitar da legitimidade social do campo jornalístico em significar os fatos sociais; mesmo que isso signifique, por exemplo, menos acesso ao seu próprio site e, de certa forma, contribua com a própria legitimação de jornais identificados com seus adversários.

Ainda que nos interesse especificamente o caso do Podemos, o recorte deste texto foi dado mais como entrada concreta para refletir sobre processos gerais do que para análises conclusivas específicas, já que não há levantamentos quantitativos. Buscamos, com essa abordagem, debater a relação entre campo jornalístico e político a partir do processo do agendamento temático e das características essenciais da notícia. Com este caráter introdutório, o texto tentou propor uma reflexão sobre comunicação política que inclua a complexidade e as possibilidades estratégicas da notícia como forma de conhecimento cristalizado no singular.

\section{Referências}

GENRO FILHO, Adelmo. O segredo da pirâmide: para uma teoria marxista do jornalismo. Florianópolis: Insular, 2012.

MCCOMBS, Maxwell. A teoria da agenda: a mídia e a opinião pública. Rio de Janeiro: Vozes, 2009.

. Nova obra discute o terceiro nível da teoria Agenda-Setting. In: Revista Pauta Geral. Ponta Grossa, v.2, n.2, jul./dez, 2015. Disponível em: http://www.revistas2.uepg.br/index.php/pauta/article/view/8017/4738.

PONTES, Felipe S. Adelmo Genro Filho e a Teoria do Jornalismo. Florianópolis: Insular, 2015.

O conceito de ideologia na teoria do jornalismo de Adelmo Genro Filho. In: Galaxia. São Paulo, n. 32, p. 151-162, ago. 2016. Disponível em: http://dx.doi.org/10.1590/1982-25542016223601

INTELECTUALES y activistas llaman a "recuperar la soberanía popular" con una candidatura para las europeas”. Público, 14 jan. 2014. Disponível em: http:// www.publico.es/politica/intelectuales-y-activistas-llaman-recuperar.html 